
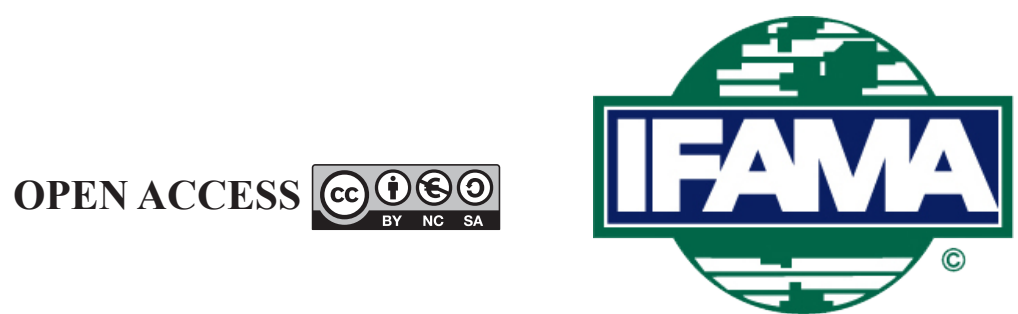

International Food and Agribusiness Management Review

Volume 21 Issue 8, 2018; DOI: 10.22434/IFAMR2017.0117

Received: 17 December 2017 / Accepted: 5 June 2018

\title{
Consumer preference and willingness to pay for tomato juice
}

\author{
RESEARCH ARTICLE \\ Yaozhou Zhu ${ }^{\mathrm{a}}$, Meng Shen ${ }^{\mathrm{b}}$, Charles A. Sims ${ }^{\mathrm{c}}$, Maurice R. Marshall ${ }^{\mathrm{c}}$, Lisa A. House ${ }^{\mathrm{d}}$, and \\ Paul J. Sarnoski ${ }^{\circledR e}$ \\ ${ }^{a}$ Sensory Scientist, Mission Foods, 5601 Executive Dr., Irving, TX 75038, USA \\ ${ }^{b}$ Data Scientist, Boston Strategic Partners, 4 Wellington Street, Suite \#3, Boston, MA 02118, USA \\ ${ }^{d}$ Professor, Food Resource Economics Department, University of \\ Florida, P.O. Box 110240, Gainesville, FL 32611, USA \\ ${ }^{c}$ Professor and ${ }^{e}$ Assistant Professor, Food Science and Human Nutrition Department, \\ University of Florida, P.O. Box 110370, Gainesville, FL 32611, USA
}

\begin{abstract}
Tomato juice has gained popularity in recent decades. However, little is known about tomato juice consumers in the United States. The goal of this research was to determine consumer attitudes towards current tomato juice offerings and willingness to pay for high flavor quality products. A sensory panel and a nation-wide survey were conducted to learn about consumer preference toward tomato juice consumption. A new "label", including taste review ratings, was incorporated into a choice experiment to verify whether this information successfully assisted consumers in their purchase decisions. Both the sensory analysis and the consumer online survey showed a demand for tomato juice with better flavor. The results suggest that a premium quality tomato juice with fresh aroma notes and better taste made from a premium tomato will encourage consumer purchase intent. Consumers would be willing to pay up to $30 \%$ more if trusted taste review score information was provided.
\end{abstract}

Keywords: tomato juice, willingness to pay, consumer survey, sensory test JEL code: Q13, M2, M3

${ }^{\oplus}$ Corresponding author: psarnoski@ufl.edu 


\section{Introduction}

The juice or juice drinks sector have struggled in the past few years as consumers have shown aversion to sugar and artificial ingredients (BI, 2017). Tomato juices are not only a low sugar containing juice but also provide a good source of vitamins and minerals such as Vitamin C, folic acid, potassium, and thiamin. Most noticeably, lycopene and other carotenoids found in tomatoes are antioxidants that have been shown to lower the risk of systemic inflammation in the overweight and obese (Ghavipour et al., 2013), cardiovascular disease (Garcia-Alonso et al., 2012), prostate, lung, stomach, pancreas, colon, rectal, esophageal, breast and cervical cancer (Giovannucci, 1999).

In this study, a premium Florida tomato was used to explore consumer preference. Florida produces $40 \%$ of the tomatoes in the United States, and supplies most of the fresh market (Putnam, 2013; USDA, 2010). The Garden Gem was reported to be statistically identical to the Maglia Rosa in taste tests and one of the top 2 among thirty-seven popular tomato varieties (Klee, 2015). The Garden Gem has also been found to be rich in volatiles important to tomato flavor (Zhu et al., 2018). A niche market for value-added, high-quality tomato juice may present a new opportunity for both tomato growers and consumers.

Few studies have examined consumer perceptions of the flavor quality of tomato juice, but Goodman, Fawcett and Barringer (2002) compared hot break and cold break treatments on tomato juice using a taste panel. However, this study did not include any purchase intent or consumer willingness to pay for a processed product. Previous research on willingness to pay for fruit and vegetable products have examined the role of quality attributes in consumer using contingent valuation. In other studies (Chen et al., 2016; Chern et al., 2003 ) on orange juice, participants were willing to pay more for not-from concentrate juice ( $\$ 1.95 /$ half gallon) compared with a half gallon of concentrated orange juice (\$1.31/half gallon). However, this research did not include sensory data. Knowledge, consumption, and willingness to pay for organic fresh tomatoes were examined in a study conducted among Spanish consumers (Mesías Díaz et al., 2012). Personal interviews with 361 regular tomato consumers and a contingent valuation was used for willingness to pay for organic and non-organic tomatoes. The results showed a mean maximum willingness to pay a premium of 0.81 $€ / \mathrm{kg}$ for the organic product. However, there was no significant link for informed consumers with regular access to organic food. As the most direct and easiest way to determine a consumer's willingness to pay, contingent valuation (name your own price) in the sensory test is used extensively to estimate how much people value a product that is not yet on the market. Despite these advantages, the "name your own price" method suffers a serious drawback - that the respondents may not accurately state their price sensitivity (Chhabra, 2015) because they may not consider the willingness to pay question they answer a reflection of a real-life purchase scenario.

In another study, House et al. (2011) examined the relationship between appearance and purchase patterns for citrus (mandarin oranges). Equal numbers of consumers from three cities (Tampa, FL, Chicago, IL and Baltimore, MD) were intercepted at shopping malls to participate in a taste test where they rated different varieties of mandarins for various sensory characteristics and answered questions about whether they would purchase or consume the varieties. The results of House et al. (2011) showed flavor was the most important factor for adults and children to increase their willingness to purchase or to consume a mandarin orange. Other factors such as number of seeds, size of fruit, color, and overall appearance were less important.

The objective of this research was to elicit consumer's preferences and willingness to pay for tomato juice in order to fill the knowledge gap left by a lack of preference and sensory marketing research on tomato juice in the United States. The intent was to find which characteristics motivate consumers to drink tomato juice and whether consumers are willing to pay a premium price for a healthier and better-tasting product. In this regard, processed tomato juices were offered and the preference pattern of panelists participating in a tomato juice sensory panel at the University of Florida were examined. These participants evaluated a high quality flavor product, Garden Gem tomato juice, and were asked about overall liking and their willingness to pay more for Garden Gem juice compared with other products (commercial and widely used plum tomato-Roma) 
tasted. An online national consumer survey was also conducted to determine preference and opinions on taste quality of tomato juice. As part of the online survey, a label system, including taste review ratings was tested to verify whether this information influences consumers in their purchase decisions.

\section{Materials and methods}

\subsection{Tomatoes}

Fully ripe Garden Gem tomatoes were harvested in Summer 2015 (Season 1) from a field (Live Oak, FL) and in Fall 2015 (Season 2) from a greenhouse (Gainesville, FL). Ripe Roma tomatoes were purchased from local Publix (Gainesville, FL, USA) and Winn-Dixie (Gainesville, FL, USA) grocery stores in both seasons.

\subsection{Juice processing}

Twenty pounds of tomatoes from each cultivar were cut into three pieces by toss and chop kitchen scissors (Comfify, Fernadale, WA, USA). The tomato pieces were then fed into a tomato electric milling machine (Model 2400, O.M.R.A. MTD, Brooklyn, NY, USA) to remove the skin and seeds. The puree produced was continuously fed into a steam kettle and heated (a process called "hot break") at $95^{\circ} \mathrm{C}$ for 3 minutes. Then the hot break juice was poured into a sanitized carboy and stored at $4{ }^{\circ} \mathrm{C}$. Later, the juice was pasteurized (Model 5024-F $25 \mathrm{HV}$, Microthermics, Raleigh, NC, USA) at $73{ }^{\circ} \mathrm{C}$ for 30 seconds and stored in another newly sanitized carboy at $4{ }^{\circ} \mathrm{C}$. The entire process was repeated three times for each variety. A commercial Campbell's Low Sodium Tomato Juice (Campbell Soup Company, Camden, NJ, USA) was purchased from Publix for comparison with the sample juices.

\subsection{Sensory panel}

Recruiting for the sensory analysis was done through e-mails and announcements posted around the Food Science and Human Nutrition Department at the University of Florida (UF) Gainesville campus. Panelists were screened based on their familiarity with tomato juice as well as their frequency of consumption and availability. Only those panelists who consumed tomato juice were selected to participate.

The sensory laboratory in the Food Science and Human Nutrition Department at UF has ten individual booths with computer workstations. Panelists were seated, assigned a corresponding panelist number, and asked to sign in to the sensory program (CompuSense ${ }^{\circledR}$ Five Sensory Analysis Software for Windows, CompuSense, Guelph, Canada) for the session. Each booth was furnished with a tray containing water, crackers, a napkin, and a refuse cup.

Tomato juice consumers (119 in October 2015; 119 in February 2016) were invited to rate their purchase intent (1-very unlikely to purchase, 5-very likely to purchase) and willingness to pay (name their own price for a $64 \mathrm{oz}$. juice, with a reference price range of \$1.98-3.98 provided) for each product before and after the three types of tomato juice samples were tasted. The three thermally processed juices (Garden Gem, Roma, and commercial juice) were randomly coded with three-digit numbers and presented in a balanced experimental design. All the samples were served at room temperature; the pilot juices (Garden Gem and Roma) contained no additives. The panelists received the same questionnaire for both the October and February sessions. The purchase intent and name your own price data collected (Table 3 ) was subjected to a 1-way analysis of variance (ANOVA) to identify any differences among means between the cultivars, Duncan's multiple-range test for mean separation was conducted. Differences were considered significant at an alpha level of less than or equal to 0.05 .

In the second part of the experiment, panelists were asked a series of questions concerning demographics, consumer behavior towards tomato juice, and perceptions about Florida tomatoes. In the third part of the experiment, participants were asked what they considered to be the most important attributes for drinking 
tomato juice and for not purchasing tomato juice. A set of twenty-nine attributes offered to panelists were generated and summarized from a previous focus group consisting of regular tomato juice consumers in Fall 2014. These attributes were rated by sensory analysis participants using a 5-point scale (1-strongly disagree, 5-strongly agree).

\subsection{Online consumer survey}

A nationwide online consumer survey was conducted in the Fall of 2016 (from September 7 to September 12, 2016). Participants age eighteen or above were recruited according to the U.S demographic criteria provided by the United States Census Bureau (USCB, 2012). A total of 1,299 participants qualified from among the 1,864 participants, after excluding those who did not complete the survey, declined the privacy policy, or would not want to consume tomato juice under any circumstances. Among these 1,299 qualifiers, 69.9\% (909 respondents) completed the screening questions satisfactorily. Three hundred and sixteen consumers were excluded from the survey because they either failed the validation questions used to control for response quality (Jones et al., 2015) or were below the age of eighteen.

The survey consisted of four sections. In the first section, participants were asked nutrition and health related questions, then questioned about their consumer behavior towards tomato juice, labels, and perceptions about Florida tomatoes specifically. In the second section, individuals were asked their opinions on the most important attributes for purchasing or not purchasing tomato juice. The attributes were the same as those used in the sensory analysis survey conducted previously. These attributes were rated by survey participants on a 5-point scale (1-strongly disagree, 5-strongly agree). The third section was a set of choice experiment questions (see next section) designed to elicit participants willingness to pay when given a new labeling system that included taste review scores. The final section was a set of demographic questions regarding their socioeconomic status, age, gender, income, and education.

\subsection{Choice experiment}

In each question, individuals were asked to select from one of two options describing tomato juice attributes or a third option that consisted of the statement "I wouldn't purchase either product" (Figure 1). To identify important tomato juice attributes, the sensory analysis results reflecting tomato juice purchasing intent were employed. Four attributes were selected for inclusion in the choice experiment: price, taste review, origin, and concentrate/ingredients added. The prices offered were $\$ 1.98,2.98$, and 3.98, reflecting the range of tomato juice prices in grocery stores during the period of the study. The taste review consisted of three levels: 2.5 stars, 3.5 stars and 4.5 stars in a 5-star consumer taste review system. "From Florida" as the origin or none was the third attribute. For concentrate/ingredients combination, the following three options were included: from concentrate, ingredients added; not from concentrate, no ingredients added; not from concentrate, ingredients added. The unrealistic combination "from concentrate, no ingredients added" was excluded.

A full factorial experimental design that included all possible combinations would require 2,916 choice sets. Since it is not reasonable to ask consumers to select from such a large number of choice sets, 15 purchasing

\begin{tabular}{|c|}
\hline Tomato Juice \\
\hline$\$ 2.98$ \\
\hline 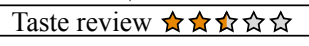 \\
\hline $\begin{array}{l}\text { Not from concentrate } \\
\text { Ingredients added }\end{array}$ \\
\hline
\end{tabular}

○

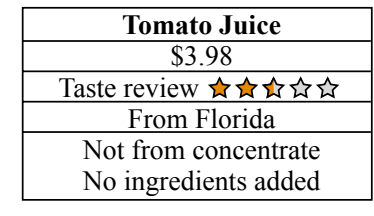

○ I wouldn't purchase
either product

Figure 1. Example of the choice set. 
scenarios were generated via a fractional experimental design to maximized-efficiency. To avoid possible ordering effects, the choice sets were randomized except for the alternative placed last.

\subsection{Group segmentation}

A factor analysis was used to segment participants into groups according to their opinions on tomato juice consumption. All of the variables were examined with both a chi-square test and a 1-way ANOVA using the SAS 9.4 software package (SAS Institue Inc, Cary, NC, USA).

\section{Theory}

Choice experiments are based on the assumption that consumers make rational decisions and that the decision will be based on maximization of utility they perceive from a given set of alternatives. For an individual consumer $i$, the utility of choosing alternative $k$ can be expressed as:

$$
U_{k i}=V_{k i}+\varepsilon_{k i}
$$

where $\mathrm{V}_{\mathrm{ki}}$ is the deterministic part of utility that can be explained by the model and $\mathrm{e}_{\mathrm{ki}}$ captures the unobserved factors that may affect utility. The observed part of the utility function is assumed to be linear in parameters, and the probability that individual $i$ would choose alternative $k$ over alternative $j$ is:

$$
P_{k i}=P\left(V_{k i}+\varepsilon_{k i}>V_{j i}+\varepsilon_{j i}\right)=P\left(\varepsilon_{j i}<V_{k i}-V_{j i}+\varepsilon_{k i}\right) \forall j \neq k ; k \in C_{i}
$$

where $\mathrm{C}_{\mathrm{i}}$ denotes the choice set that respondent $i$ faces. Therefore, the probability of choosing alternative $k$ is the cumulative distribution function of the random error at point $\left(\mathrm{V}_{\mathrm{ki}}-\mathrm{V}_{\mathrm{ji}}+\varepsilon_{\mathrm{ki}}\right)$. If the unobserved factors are iid of type I extreme value distributed, the choice probability can be expressed as:

$$
P_{k i}=e^{u V_{k i}} / \sum_{j=1}^{J} e^{u V_{j i}}
$$

which is the multinomial logit (MNL) model (Hensher et al., 2013; Train, 2009). The scale $u$ is inversely related to the variance of the error terms and is not identifiable in a single model, hence the estimated parameters are compounds made up of the preference and scale parameters.

Compared to the MNL model, the mixed logit model allows for variation among consumers regarding taste. Therefore, there is no specific behavioral assumption to be restricted (Train, 2009). The probability that an individual consumer $\mathrm{i}$ will choose alternative $\mathrm{k}$ is conditional on the individual specific parameter $\beta_{\mathrm{i}}$. Assuming that the coefficients vary among individuals but are stable for each consumer, the probability that an individual chooses a particular sequence of choices is the product of the conditional probability function. The integral of this product over all $\beta$ values gives the unconditional probability function:

$$
P_{k i n}=\int\left(\prod_{n=1}^{N}\left[\frac{\exp \left(\beta_{i} x_{k i n}\right)}{\Sigma_{j}^{J} \exp \left(\beta_{i} x_{j i n}\right)}\right]\right) f(\beta) d \beta
$$

where $\mathrm{N}$ represents the number of choice sets that each individual faces (Petrin and Train, 2003). The density function $f(\beta)$ is assumed to be normal, and takes the form $\beta i=b+$ sei, where $b$ is the population mean, $\mathrm{s}$ is the coefficient standard deviation and the iid random error term ei $\sim \mathrm{N}(0,1)$. If $\mathrm{s}$ is zero, the mixed logit model collapses to the MNL model. We assume that the quality attributes (taste, origin, etc.) and the opt-out alternative follow a normal distribution, while the price parameter is fixed. Because the choice probability 
for a mixed logit model has no closed form solution, the mixed logit model is estimated by maximizing the simulated log-likelihood function:

$$
\ln L=\sum_{i=1}^{N} \ln \left\{\frac{1}{R} \sum_{r=1}^{R} \prod_{t=1}^{T} \frac{e^{\beta_{i r}^{\prime} x_{i j t}}}{\sum_{j=1}^{J} e^{\beta_{i r}^{\prime} x_{i j t}}}\right\}
$$

$R$ is the number of replications and $\beta_{i r}$ is the r-th draw from $f(\beta \mid \theta)$. The individual-level coefficients can be obtained as follows using Bayes's rule:

$$
\widehat{\beta}_{\iota}=\frac{\frac{1}{R} \sum_{r=1}^{R} \hat{\beta}_{i r} \prod_{t=1}^{T} \frac{e^{\widehat{\beta}_{i r}^{\prime} x_{i j t}}}{\sum_{j=1}^{J} e^{\widehat{\beta}_{i r}^{\prime} x_{i j t}}}}{\frac{1}{R} \sum_{r=1}^{R} \prod_{t=1}^{T} \frac{e^{\widehat{\beta}_{i r}^{\prime} x_{i j t}}}{\sum_{j=1}^{J} e^{\widehat{\beta}_{i r}^{\prime} x_{i j t}}}}
$$

Based on the individual-level estimates of $\beta_{\mathrm{i}}$, each consumer's willingness to pay (WTP) for a non-price attribute can be calculated as the negative ratio of the attribute coefficient to the price coefficient (Hensher et al., 2006):

$$
W T P_{i N O N P R I C E}=-\frac{\hat{\beta}_{\text {iNONPRICE }}}{\hat{\beta}_{\text {iPRICE }}}
$$

Finally, the mixed logit model is estimated using Halton draws (Train, 2009) with 500 simulations. We specified the price coefficient to be fixed. The coefficients of non-price attributes are assumed to be normally distributed.

\section{Results}

\subsection{Sensory panel analysis}

A typical participant for the sensory testing was female, aged 18-29, with a college degree, an income of $\$ 23,000-34,999$, and a resident of central Florida. Complete demographic information for sensory panelists can be found in Tables 1 and 2 .

Consumers tend to alter purchase intent for tomato juice according to expected characteristics and experience. Since all the samples were randomized and coded with a 3-digit number, the consumer relied solely on the appearance characteristics and taste experience. The summary of the responses for purchase intent and price are presented in Table 3. After tasting, Garden Gem was most likely to be purchased by consumers at a significantly $(P<0.05)$ higher level. However, before tasting, the commercial and Garden Gem juice showed no significant difference relating to purchase intent and willingness to pay. Interestingly, consumer's willingness to pay after tasting the commercial juice fell significantly. The panelists lowered the price they would be willing to pay for the commercial juice to the extent that they would pay a price that was $30 \%$ lower when compared with the Roma (which consistently rated low in the sensory analysis both before and after taste). The vivid color and uniformity of the low sodium commercial juice may give consumers high expectations about tomato juice when other information is not available, but they are disappointed when the taste of the commercial juice fails to live up to their expectations. This meant consumer's purchase intent dropped dramatically when tested about future purchases.

On a scale from 1 (not at all important) to 5 (very important), more than $50 \%$ of the sensory testing panelists rated bad taste, lack of freshness and concerns about microbial contamination as very important attributes 
Table 1. Profile analysis of the segments (Season 1) for sensory evaluation participants according to descriptive variables $(\mathrm{N}=119){ }^{1}$

\begin{tabular}{|c|c|c|c|c|c|}
\hline \multicolumn{2}{|l|}{ Variables } & $\begin{array}{l}\text { S1 (\%) } \\
36.1\end{array}$ & $\begin{array}{l}\text { S2 (\%) } \\
39.5\end{array}$ & $\begin{array}{l}\text { S3 (\%) } \\
24.4\end{array}$ & Total (\%) \\
\hline \multirow{2}{*}{ Gender } & Male & 46.5 & 40.4 & 37.9 & 42.0 \\
\hline & Female & 53.5 & 59.6 & 62.1 & 58.0 \\
\hline \multirow[t]{5}{*}{ Age } & $<18$ & 0.0 & 2.1 & 0.0 & 0.8 \\
\hline & $18-29$ & 69.8 & 70.2 & 65.5 & 68.9 \\
\hline & $30-44$ & 14.0 & 14.9 & 13.8 & 14.3 \\
\hline & $45-65$ & 16.3 & 12.8 & 20.7 & 16.0 \\
\hline & $>65$ & 0.0 & 0.0 & 0.0 & 0.0 \\
\hline \multirow[t]{7}{*}{ Income } & $<14,999$ & 20.9 & 19.2 & 27.6 & 21.8 \\
\hline & $\$ 15,000-\$ 24,999$ & 25.6 & 36.2 & 27.6 & 30.3 \\
\hline & $\$ 25,000-\$ 34,999$ & 7.0 & 12.8 & 17.2 & 11.8 \\
\hline & $\$ 35,000-\$ 49,999$ & 16.3 & 8.5 & 3.5 & 10.1 \\
\hline & $\$ 50,000-\$ 74,999$ & 18.6 & 10.6 & 10.3 & 13.4 \\
\hline & $\$ 75,000-\$ 99,999$ & 7.0 & 4.3 & 3.5 & 5.0 \\
\hline & $>\$ 100,000$ & 4.7 & 8.5 & 10.3 & 7.6 \\
\hline \multirow[t]{7}{*}{ Education } & Less than high school & 0.0 & 8.5 & 0.0 & 3.4 \\
\hline & High school/GED & 14.0 & 8.5 & 10.3 & 10.9 \\
\hline & Some college & 11.6 & 10.6 & 6.9 & 10.1 \\
\hline & 2 -year college & 4.7 & 12.8 & 0.0 & 6.7 \\
\hline & 4-year college & 27.9 & 42.6 & 51.7 & 39.5 \\
\hline & Postgraduate & 34.9 & 10.6 & 20.7 & 21.8 \\
\hline & Doctoral degree & 7.0 & 6.4 & 10.3 & 7.6 \\
\hline \multirow[t]{7}{*}{ Florida tomato opinion ${ }^{* * *}$} & Less pesticides & 7.0 & 8.5 & 20.7 & 10.9 \\
\hline & Better tasting & 14.0 & 21.3 & 20.7 & 18.5 \\
\hline & Nutritious & 11.6 & 8.5 & 3.5 & 8.4 \\
\hline & Environmentally friendly & 14.0 & 12.8 & 10.3 & 12.6 \\
\hline & Safer & 9.3 & 8.5 & 6.9 & 8.4 \\
\hline & Premium quality & 9.3 & 8.5 & 6.9 & 11.8 \\
\hline & None of the above & 11.6 & 14.9 & 6.9 & 29.4 \\
\hline
\end{tabular}

that prevented them from purchasing tomato juice (Figure 2). This demonstrates a need for a tomato juice that is enhanced with fresh tomato flavor.

More than $50 \%$ of consumers purchased tomato juice from grocery stores, restaurants, or at a bar with an alcoholic drink (Figure 3). Approximately $40 \%$ of the panelists had never consumed tomato juice on an airplane or made fresh juice at home. Interestingly, a study by Firger (2015) revealed an increased preference for tomato juice on airplanes compared with consumption at normal atmospheric pressure. Results pertaining to the habits of tomato juice consumption confirmed that most college students drank tomato juice outside the home, with or without blending it with an alcoholic drink.

A factor analysis was used to segment tomato juice consumers into different groups according to their opinion on characteristics for purchase of tomato juice. Variables were examined with both a chi-square test and a 1-way ANOVA) using SAS 9.4. The segmentation was determined by eigenvalues $(>1)$ from fifteen factors that influence tomato juice consumption. Three segments (Table 4) of consumers were formed in Summer and Fall, with a slight seasonal variation among consumers. Segment 1 from the sensory panel 
Table 2. Profile analysis of the segments (Season 2) for sensory evaluation participants according to descriptive variables $(\mathrm{N}=119) .{ }^{1}$

\begin{tabular}{|c|c|c|c|c|c|}
\hline \multicolumn{2}{|l|}{ Variables } & $\begin{array}{l}\text { S1 (\%) } \\
47.1\end{array}$ & $\begin{array}{l}\text { S2 (\%) } \\
26.0\end{array}$ & $\begin{array}{l}\text { S3 (\%) } \\
26.9\end{array}$ & Total (\%) \\
\hline \multirow[t]{2}{*}{ Gender } & Male & 48.2 & 38.7 & 34.4 & 42.0 \\
\hline & Female & 51.8 & 61.3 & 65.6 & 58.0 \\
\hline \multirow[t]{5}{*}{ Age } & $<18$ & 0.0 & 3.2 & 0.0 & 0.8 \\
\hline & $18-29$ & 78.6 & 71.0 & 71.9 & 74.8 \\
\hline & $30-44$ & 10.7 & 6.5 & 12.5 & 10.1 \\
\hline & $45-65$ & 10.7 & 19.4 & 12.5 & 13.4 \\
\hline & $>65$ & 0.0 & 0.0 & 3.1 & 0.8 \\
\hline \multirow[t]{7}{*}{ Income } & $<14,999$ & 33.9 & 32.3 & 21.9 & 30.3 \\
\hline & $\$ 15,000-\$ 24,999$ & 21.4 & 19.4 & 43.8 & 26.9 \\
\hline & $\$ 25,000-\$ 34,999$ & 8.9 & 19.4 & 12.5 & 12.6 \\
\hline & $\$ 35,000-\$ 49,999$ & 12.5 & 9.7 & 9.4 & 10.9 \\
\hline & $\$ 50,000-\$ 74,999$ & 8.9 & 9.7 & 3.1 & 7.6 \\
\hline & $\$ 75,000-\$ 99,999$ & 8.9 & 6.5 & 6.3 & 7.6 \\
\hline & $>\$ 100,000$ & 5.4 & 3.2 & 3.1 & 4.2 \\
\hline \multirow{7}{*}{ Education $^{* *}$} & Less than high school & 0.0 & 6.5 & 0.0 & 1.7 \\
\hline & High school/GED & 7.1 & 9.7 & 18.8 & 10.9 \\
\hline & Some college & 10.7 & 9.7 & 21.9 & 13.4 \\
\hline & 2-year college & 1.8 & 12.9 & 6.3 & 5.9 \\
\hline & 4-year college & 35.7 & 32.3 & 21.9 & 31.1 \\
\hline & Postgraduate & 33.9 & 22.6 & 18.8 & 26.9 \\
\hline & Doctoral degree & 10.7 & 6.5 & 12.5 & 10.1 \\
\hline \multirow[t]{7}{*}{ Florida tomato opinion ${ }^{* * *}$} & Less pesticides & 12.5 & 12.9 & 9.4 & 11.8 \\
\hline & Better tasting & 21.4 & 16.1 & 28.1 & 21.8 \\
\hline & Nutritious & 3.6 & 6.5 & 3.1 & 4.2 \\
\hline & Environmentally friendly & 14.3 & 3.2 & 9.4 & 10.1 \\
\hline & Safer & 3.6 & 6.5 & 3.1 & 4.2 \\
\hline & Premium quality & 17.9 & 22.6 & 3.1 & 15.1 \\
\hline & None of the above & 26.8 & 32.3 & 43.8 & 32.8 \\
\hline
\end{tabular}

Table 3. Purchase intent and name your own price of sensory testing panelists before and after sensory analysis $(\mathrm{N}=119){ }^{1}$

\begin{tabular}{|c|c|c|c|c|c|c|c|c|}
\hline & \multirow[t]{2}{*}{ Product } & \multicolumn{3}{|c|}{ Purchase intent $^{2}$} & \multicolumn{4}{|c|}{ Name your own price ${ }^{3}$} \\
\hline & & Before taste & After taste & Difference & Before taste & After taste & Difference & Premium \\
\hline \multirow[t]{3}{*}{ S1 } & Garden Gem & $3.34^{\mathrm{a}}$ & $3.1^{\mathrm{a}}$ & $-0.24^{b}$ & $2.89^{\mathrm{a}}$ & $2.64^{\mathrm{a}}$ & $-0.24^{b}$ & - \\
\hline & Commercial & $3.48^{\mathrm{a}}$ & $2.7^{\mathrm{b}}$ & $-0.50^{\mathrm{a}}$ & $2.77^{\mathrm{a}}$ & $2.27^{\mathrm{a}}$ & $-0.29^{\mathrm{ab}}$ & 0.37 \\
\hline & Roma & $2.83^{\mathrm{b}}$ & $2.3^{\mathrm{c}}$ & $-0.29^{\mathrm{ab}}$ & $2.39^{\mathrm{b}}$ & $2.10^{\mathrm{b}}$ & $-0.50^{\mathrm{a}}$ & 0.54 \\
\hline \multirow[t]{3}{*}{ S2 } & Garden Gem & $3.13^{\mathrm{a}}$ & $2.98^{\mathrm{a}}$ & $-0.15^{c}$ & $2.62^{\mathrm{a}}$ & $2.46^{\mathrm{a}}$ & $-0.16^{\mathrm{c}}$ & - \\
\hline & Commercial & $3.32^{\mathrm{a}}$ & $2.42^{\mathrm{b}}$ & $-0.90^{\mathrm{a}}$ & $2.75^{\mathrm{a}}$ & $2.05^{\mathrm{b}}$ & $-0.48^{\mathrm{b}}$ & 0.41 \\
\hline & Roma & $2.66^{\mathrm{b}}$ & $2.23^{b}$ & $-0.43^{b}$ & $2.34^{\mathrm{b}}$ & $1.86^{\mathrm{b}}$ & $-0.70^{\mathrm{a}}$ & 0.60 \\
\hline
\end{tabular}

${ }_{1}^{1}$ S1-Season 1, S2-Season 2; difference were calculated as the score difference before and after.

2 1-Definitely would not buy, 5-Definitely would buy.

${ }^{3}$ Premium was calculated as the average price of Garden Gem (after taste) minus the average price of another variety (after taste). 


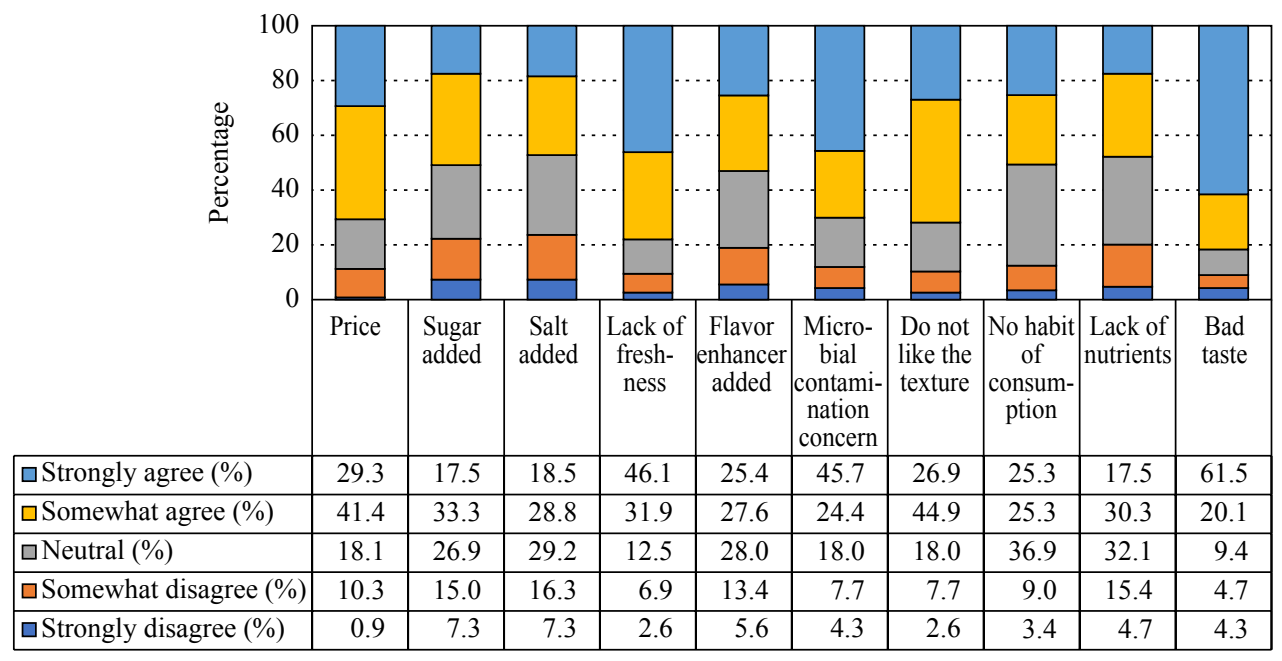

Figure 2. Characteristics preventing consumer purchase of tomato juice for sensory panelists $(\mathrm{N}=238)$.

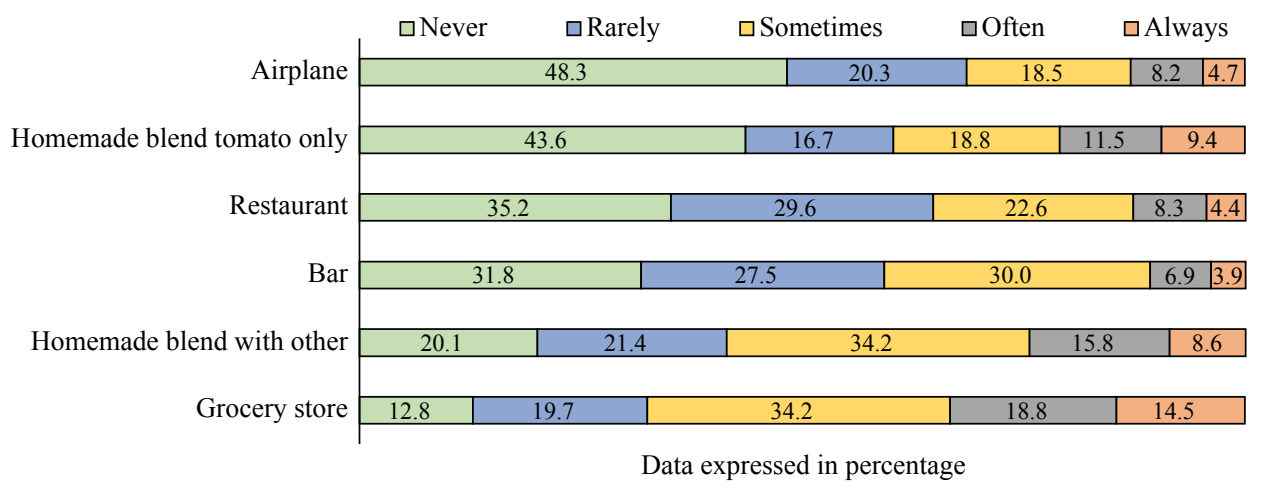

Figure 3. Occasions and frequency for tomato consumption for sensory panelists $(\mathrm{N}=238)$.

Table 4. Factor scores for sensory panelists (Season 1 and Season 2) segmentation according to tomato juice consumption opinions.

\begin{tabular}{lccc}
\hline Variables & F1 & F2 & F3 \\
\hline Freshness & 0.305 & 0.012 & $0.388^{*}$ \\
Nutrition and health benefit & $0.444^{*}$ & 0.069 & 0.353 \\
Sourness & -0.088 & $-0.612^{*}$ & 0.172 \\
Saltiness & -0.133 & $-0.682^{*}$ & 0.077 \\
Sweetness & -0.063 & $-0.527^{*}$ & 0.245 \\
Safety & $0.286^{*}$ & -0.045 & 0.153 \\
Tomato flavor & 0.114 & -0.097 & $0.328^{*}$ \\
Color & $0.318^{*}$ & -0.217 & -0.173 \\
Type & $0.396^{*}$ & -0.112 & -0.173 \\
Origin & $0.608^{*}$ & -0.062 & -0.057 \\
Organic & $0.707^{*}$ & 0.126 & 0.031 \\
Additive free & $0.657^{*}$ & 0.109 & 0.159 \\
Texture & 0.105 & $-0.341^{*}$ & -0.264 \\
Brand & $0.479^{*}$ & -0.283 & -0.394 \\
Calories & $0.376^{*}$ & -0.071 & -0.177 \\
\hline
\end{tabular}

${ }^{*}$ Denotes the highest factor score for the variable. 
represents consumers $(36.13 \%$ Season $1 ; 47.06 \%$ Season 2$)$ who desired a safe, nutritious and healthy product, with a good appearance, from a trusted brand tomato juice. About 39.05 and $26.05 \%$ of consumers were represented in Segment 2 in Season 1 and Season 2, respectively. Consumers from Segment 2 most favored a combination of sourness, sweetness, saltiness, and texture. About $24.37 \%$ (Season 1) and 36.89\% (Season 2) of consumers comprised Segment 3, who consumed tomato juice for its freshness and tomato flavor. When questioned about opinions on "Florida Tomatoes," these tomatoes were perceived to be better tasting and were rated significantly higher. All segments agreed on this, indicating that sensory panelists in this study had a generally good impression of Florida tomatoes.

The open-ended contingent valuation method was used to estimate panelist' willingness to pay. This is a simple way to evaluate multiple products in a sensory test. Panelists' were asked to name the price they were willing to pay after being shown the market price range for reference. A price premium of $\$ 0.37$ and 0.41 for Garden Gem in the both seasons (Summer and Fall) respectively was found when compared with commercial juice $(64 \mathrm{oz})$.

\subsection{Online consumer survey demographic and opinion data}

The descriptive statistics of the national online survey participants is given in the Table 5. The sample generally corresponded well with the U.S. census population of 2010. Survey participants and their families generally reported being in good health. Of the participants (Table 6), 73.4 and 52.4\% answered that nobody in their household had diabetes or high cholesterol, respectively. However, the rate of those who identified as overweight was $34.8 \%$ for the participants themselves and $20.5 \%$ for other household members. Many reported trying diet $(48.1 \%)$ or exercise $(59.7 \%)$ in the past year. Approximately three-quarters $(76.1 \%)$ of the participants searched for health information related to food and beverages, and $58.6 \%$ of these searched for that type of material at least once a week. Therefore, it is not surprising that $70.3 \%$ of the survey-takers claimed moderate or above average knowledge of the health benefits of tomato juice on a 7-point scale (1not at all knowledgeable, 4-moderate knowledge, 7-expert).

Participants consumed tomato juice at a moderate frequency and during different occasions (Figure 4). Most consumers purchased tomato juice from the grocery store $(75.4 \%)$, made it at home (47.2\%), or drank it in a bar (35.1\%). A total of 32.3 and $24.4 \%$ of the participants indicated they had consumed tomato juice during the previous week and previous month, respectively, with more than $80 \%$ consuming tomato juice within the past year. With respect to reading labels, more than half of the survey respondents have noticed that the tomato juice could be labeled either "from concentrate" or "not from concentrate."

Views on the origin of tomato juice diverged from person to person, with generally positive remarks about Florida tomatoes (Table 7). A quarter of the participants claimed the origin of tomato juice does not matter to them, while a second quarter of respondents liked tomatoes from other states or countries such as Ohio, South Carolina, Italy, Canada, or Mexico. In particular, 28.5 and $21.8 \%$ of respondents preferred to purchase tomatoes from California or Florida, respectively. When asked about their impression of Florida tomatoes, the top answers given by participants were "premium quality," "taste better," and "more nutrients".

Similar to the opinion of the sensory testing panelists, a vast majority of the online survey respondents agreed that the problem with tomato juice is its "lack of freshness," "bad taste," and "microbial contamination concern", all rated at 4 or 5 on average (1-strongly disagree, 5-strongly agree) (Figure 5). There has not been a foodborne pathogen outbreak associated with tomato juice in the United States in the past few decades. Perhaps participants may have associated "microbial contamination concern" with recent U.S. recalls related to foodborne illness outbreaks linked to fresh tomato consumption. More than $60 \%$ of the participants agreed that "sugar added" and "salt added" as well as "price" were the major reasons that prevented them from purchasing tomato juice. 
Table 5. Descriptive statistics for the online survey participants ( $\mathrm{N}=983)$.

\begin{tabular}{|c|c|c|}
\hline Variable & Group & Percentage \\
\hline \multirow[t]{2}{*}{ Gender } & Female & 53.6 \\
\hline & Male & 46.4 \\
\hline \multirow[t]{2}{*}{ Family size } & $1-3$ & 65.6 \\
\hline & 4 or more & 34.4 \\
\hline \multirow{2}{*}{ Children under 18} & $0-2$ & 74.7 \\
\hline & 2 or more & 27.4 \\
\hline \multirow[t]{8}{*}{ Income level } & $<\$ 15,000$ & 7.8 \\
\hline & $\$ 15,000-\$ 24,999$ & 8.2 \\
\hline & $\$ 25,000-\$ 34,999$ & 11.6 \\
\hline & $\$ 35,000-\$ 49,999$ & 11.4 \\
\hline & $\$ 50,000-\$ 74,999$ & 20.2 \\
\hline & $\$ 75,000-\$ 99,999$ & 19.7 \\
\hline & $\$ 100,000-\$ 149,999$ & 13.7 \\
\hline & $\$ 150,000$ or over & 7.0 \\
\hline \multirow[t]{3}{*}{ Age (years) } & $18-34$ & 24.8 \\
\hline & $35-64$ & 54.2 \\
\hline & 65 and above & 21.0 \\
\hline \multirow[t]{5}{*}{ Race } & White/Caucasian & 83.5 \\
\hline & African American & 4.2 \\
\hline & Hispanic & 4.5 \\
\hline & Asian & 3.0 \\
\hline & Other & 4.8 \\
\hline \multirow[t]{6}{*}{ Education } & Less than high school & 1.5 \\
\hline & High school/GED & 15.0 \\
\hline & Some college & 21.3 \\
\hline & 2-year college & 8.6 \\
\hline & 4-year college & 33.0 \\
\hline & Postgraduate & 20.7 \\
\hline \multirow[t]{5}{*}{ Region } & Northeast & 23.0 \\
\hline & Midwest & 19.0 \\
\hline & South & 33.6 \\
\hline & West & 24.1 \\
\hline & Other & 0.2 \\
\hline
\end{tabular}

When it comes to their reason for tomato juice consumption, online survey participants were divided into two segments using a factor analysis. Segment 1 comprised $45.2 \%$ of the respondents and focused on taste and additive free as reasons to purchase tomato juice. The remaining 54.8\% (Segment 2) considered natural tomato flavor, freshness, nutrition and label information (origin, organic, concentrate) as their motivation to purchase.

\subsection{Survey willingness to pay}

Both the multinomial logit model (MNL) and mixed logit model (MXL) were tested to determine the effects of price, taste review, origin, and type of juice on consumers' willingness to purchase. Both models showed a similar trend (Table 8), but the MXL model have a smaller absolute log likelihood value $(-10,743)$ than that of MNL $(-12,998)$, indicating a better fit. 
Table 6. Health and lifestyle information related to tomato juice consumption for online consumer survey participants $(\mathrm{N}=983)$.

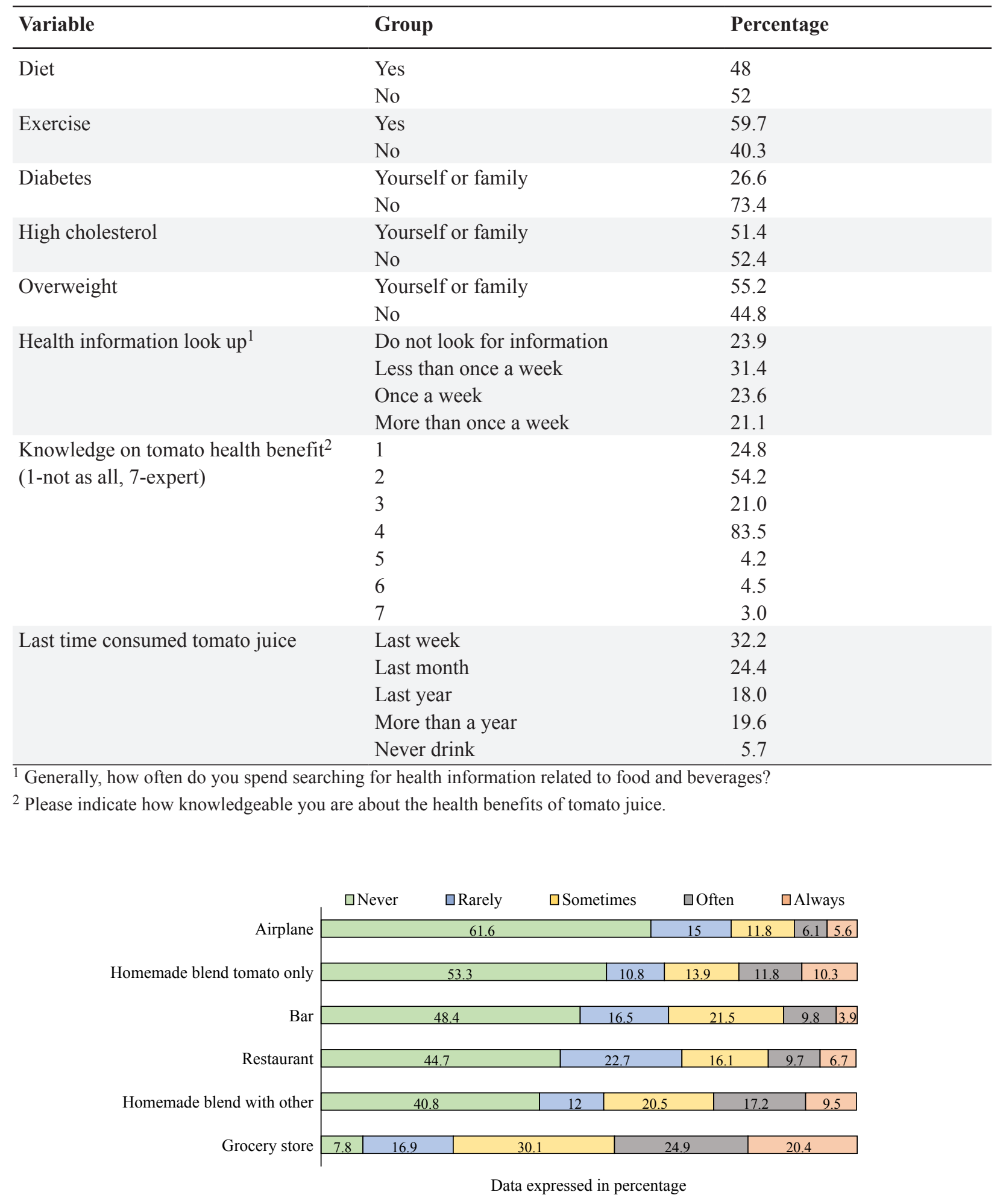

Figure 4. Occasions and frequency of tomato juice consumption for online consumer survey participants $(\mathrm{N}=983)$. 
Table 7. Label and tomato origin opinion for online consumer survey respondents $(\mathrm{N}=983) .{ }^{1}$

\begin{tabular}{llc}
\hline Variable & Group & Percentage \\
\hline Aware of concentrate label & Yes & 59.6 \\
Origin $^{* *}$ & No or do not know & 40.4 \\
& Canada & 5.5 \\
& California, US & 28.5 \\
& Florida, US & 21.8 \\
& Italy & 8.5 \\
& Mexico & 3.1 \\
& Spain & 4.7 \\
& Other & 2.7 \\
& Does not matter & 25.3 \\
Impression of Florida tomatoes $^{* * *}$ & Grown using less pesticides & 9.3 \\
& Taste better than other tomatoes & 12.1 \\
& More nutritious & 12.4 \\
& Environmentally friendly & 11.4 \\
& Safer & 9.7 \\
& Premium quality & 19.6 \\
& Willing to pay more & 7.4 \\
& Other & 1.4 \\
& None of the above & 16.6 \\
\hline${ }^{1}$ Sample questions: ${ }^{*}$ are you aware that tomato juice can be labeled as "from concentrate" or "not from concentrate"?; ${ }^{* *}$ given the \\
option, would you prefer to purchase tomato juice from a specific origin, if so, please indicate which origin(s) you prefer (select all \\
that apply)?; ${ }^{* * *}$ which of the following statements about "Florida tomatoes" do you agree with (select all that apply)?
\end{tabular}

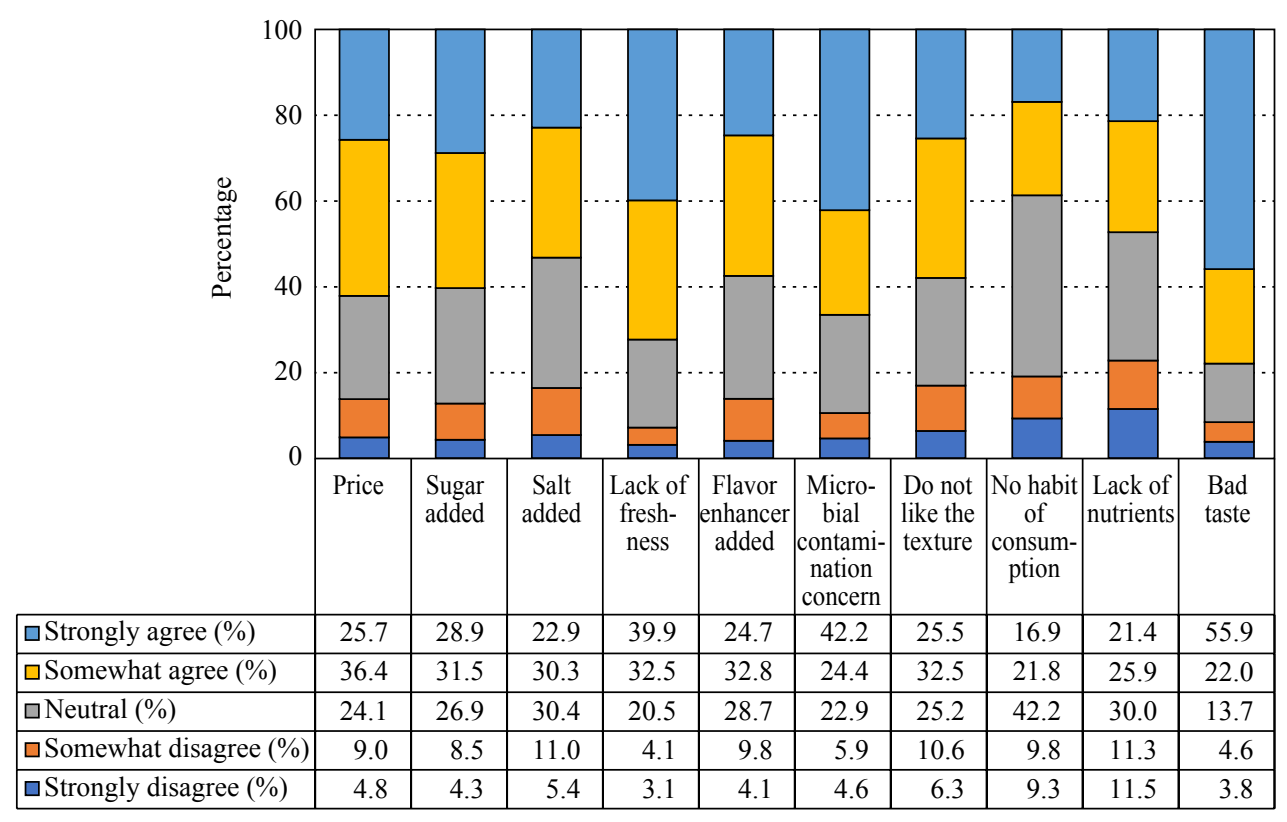

Figure 5. Characteristics preventing consumer purchase of tomato juice for sensory panelists $(\mathrm{N}=983)$. 
Table 8. Utility function parameter estimates for online consumer survey respondents. ${ }^{1,2}$

\begin{tabular}{|c|c|c|c|c|c|c|}
\hline \multirow[t]{3}{*}{ Variable } & \multirow{2}{*}{\multicolumn{2}{|c|}{ MNL }} & \multicolumn{4}{|l|}{ MXL } \\
\hline & & & \multicolumn{2}{|l|}{ Mean } & \multicolumn{2}{|l|}{ St. Dev } \\
\hline & Coef & SE & Coef & SE & Coef & SE \\
\hline Price & $-0.52^{* * *}$ & 0.02 & $-0.67^{* * *}$ & 0.02 & & \\
\hline Taste review score & $0.68^{* * *}$ & 0.02 & $0.87^{* * *}$ & 0.03 & $0.74^{* * *}$ & 0.03 \\
\hline Origin & $0.35^{* * *}$ & 0.03 & $0.33^{* * *}$ & 0.05 & $0.96^{* * *}$ & 0.04 \\
\hline Type & $0.54^{* * *}$ & 0.02 & $0.73^{* * *}$ & 0.04 & $0.82^{* * *}$ & 0.03 \\
\hline None & $1.83^{* * *}$ & 0.09 & $1.57^{* * *}$ & 0.11 & & \\
\hline Log-likelihood & $-12,998$ & & $-10,743$ & & & \\
\hline No. of observations & 13,635 & & 13,635 & & & \\
\hline No. of respondents & 909 & & 909 & & & \\
\hline
\end{tabular}

Corresponding with economic theory, the price coefficients were negative and significant for all model specifications, indicating that as the price increased, the likelihood to purchase decreased. The coefficients for taste review were significantly positive (0.68), suggesting that consumers were more favorable of tomato juice with increasing taste review ratings. The results for tomato type coefficient were significant, which demonstrated that consumers in general prefer tomato juice without ingredients added and not from concentrate on the label. A relatively small, but significant, coefficient was found in the origin parameter. This suggests that consumers may choose tomato juice with a Florida origin more often than a tomato juice with no origin information.

The WTP estimates were derived from the MXL model coefficients shown in Table 9. Consumers were willing to pay $\$ 1.34$ more for premium tomato juice as the taste review score increased by one star. Participants would pay $\$ 1.11$ more for tomato juice with no ingredients added or for not from concentrate. However, only a $\$ 0.51$ premium was observed when a tomato juice was labeled "From Florida" compared to no additional information. This shows an interest in where the juice is from, however, it appears added ingredients and taste review scores are more important in the decision process. After the choice experiment, $75 \%$ of the participants indicated they found the taste review helpful in making the decision about which product they chose during the experiment.

\section{Discussion}

A study that explores the preference of tomato juice consumers using pilot products as a case to assess the sensory quality before commercialization is important. Insights into taste message communication and the formulation of consumer preference is critical not only for food product developers for innovation or rennovation, but also for manufactures to design efficient marketing strategies to satisfy consumers/ increase sales. This research provides empirical data indicating that people consume this low calorie low sugar containing product for the healthy ingredients (Table 4). The findings in this study also show that

Table 9. Willingness to pay (WTP) estimates for online consumer survey respondents.

\begin{tabular}{lllll}
\hline WTP & Mean & Standard deviation & $\begin{array}{l}\text { Lower 95\% } \\
\text { confidence interval }\end{array}$ & $\begin{array}{l}\text { Upper 95\% } \\
\text { confidence interval }\end{array}$ \\
\hline Taste review score & 1.34 & 0.95 & 1.28 & 1.40 \\
Origin & 0.51 & 1.14 & 0.44 & 0.59 \\
Type & 1.11 & 0.98 & 1.04 & 1.17 \\
\hline
\end{tabular}


consumers have a high demand for tomato juice that tastes good and would be willing to pay a premium for such a product (Tables 3 and 9). This is consistent with the results of both the taste panel and online survey. For the taste panel data, the change in preference could be a result of the taste test itself. Consumers liked the appearance of the commercial tomato juice when the taste experience was not available (i.e. before tasting), but when given the chance to experience the taste, participants significantly favored Garden Gem with respect to both overall likability and tomato flavor. It is likely that the sensory experience affected the purchase intent and may further influence purchase behavior. For the online survey choice experiment, $75 \%$ of the nationwide tomato juice consumers indicated they found the taste review helpful in making a decision about which product they chose during the experiment. However, fresh flavor was rated as the most important product attribute. The product with the higher taste review score was rated only second in importance to fresh tomato flavor, which may indicate that consumers are willing to pay more for a premium, closer to fresh tomato flavor tomato juice. Specifically, good taste may be linked to fresh tomato notes, which most processed tomato juice lacks.

The online survey respondents exhibited similar patterns with sensory panelists regarding tomato juice consumption and preferences, although there were slight differences in opinions regarding the willingness to pay for premium products and Florida tomatoes, as may be expected with a national panel compared to one conducted in Florida.

In daily life, the consumer sees the product in the grocery store with a label. But in the online survey, the labels only contain specific information, such as origin, type, and nutrition, which taken together contain specific information that may influence purchase behavior. To incorporate taste into an online survey where participants can't experience the product, a taste review score was included in the experiment. This may be similar to an in-store experience where consumers cannot sample the products before making a purchase.

With the exception of our pilot juice made from Garden Gem and Roma, none of the tomato juice products currently on the market fulfills the standard of being "without added ingredients and not from concentrate". However, among all the current tomato juice products, two relatively new products make the claim of being "not from concentrate" and are sold at a premium price. Recently, Hirzel Canning Company and Farms launched a new tomato juice labeled Dei Fratelli's Truly ${ }^{\mathrm{TM}}$ Tomato! Juice (2015). Made from northwest Ohio and southeast Michigan vine tomatoes, the juice has a "not from concentrate" claim, but with sea salt added. Similarly, Lakewood's pure organic tomato juice (2016) added organic lemon juice to the product and is sold as a high end juice.

In this study, participants seem to link their preference according to their familiarity of origin (Florida) and juice type. Florida tomatoes may sound familiar to consumers, thereby increasing their confidence about the quality of the product (Sheth et al., 1991), or directly impacting the value of the food due to its symbolic or affective role (Stefani et al., 2006). The preference for tomato juice that is not from concentrate may largely be due to the popularity of the positive image of NFC (not from concentrated) orange juice. Florida consumers in taste panels regarded Florida tomatoes as "premium quality" while national online survey participants established that Florida tomatoes "taste better".

\section{Conclusions}

Overall, this research suggests that consumers would be willing to pay a premium price for tomato juice with high sensory quality. Some effort is needed to improve the sensory quality of the tomato juice currently on the market. Perhaps not surprisingly, poor taste discouraged consumers' purchase intent and willingness to pay for both sensory panelists and online survey participants. Consumers demand a premium quality tomato juice with a fresh note and better taste such as that provided by the Garden Gem tomato. In order to promote the consumption and purchase of tomato juice, improving the quality and proper communication of this information about improved quality to consumers is key to increasing consumer willingness to pay. 
This study is not without limitations. The online choice experiment is hypothetical, which creates the opportunity for hypothetical bias. Future research could consider the use of non-hypothetical choice experiments or auctions to further understand WTP for tomato juice. Additionally, this experiment was not designed to allow for interaction between the independent variables. Future research investigating the interactions between attributes would also allow for a deeper understanding of consumer willingness to pay.

\section{Acknowledgements}

The authors thank the University of Florida Institute of Food and Agricultrural Sciences for funding support for this project.

\section{References}

Beverage Industry (BI). 2017. Health and wellness drives growth of vegetable juices, juice smoothies. Oct 17. Available at: http://tinyurl.com/y8h2vwaf.

Chen, X., Z. Gao, L. House, J. Ge, C. Zong and F. Gmitter. 2016. Opportunities for Western food products in China: the case of orange juice demand. Agribusiness 32(3): 343-362.

Chern, W.S., N. Kaneko and G.B. Tarakcioglu. 2003. Willingness to pay for PEF-processed orange juice: evidence from an auction experiment. In: AAEA Annual Meeting, Montreal, Canada, 1-25. Available at: http://tinyurl.com/yaszkfl3.

Chhabra, S. 2015. Determining the optimal price point: using Van Westendorp's price sensitivity meter. In: Managing in recovering markets. Springer, New York, NY, USA.

Firger, J. 2015. The science behind why you drink tomato juice when you're on an airplane. Available at: http://tinyurl.com/y9a4n2v4.

García-Alonso, F., V. Jorge-Vidal, G. Ros and M. Periago. 2012. Effect of consumption of tomato juice enriched with n-3 polyunsaturated fatty acids on the lipid profile, antioxidant biomarker status, and cardiovascular disease risk in healthy women. European Journal of Nutrition 51(4): 415-424.

Ghavipour, M., A. Saedisomeolia, M. Djalali, G. Sotoudeh, M.R. Eshraghyan, A.M. Moghadam. 2013. Tomato juice consumption reduces systemic inflammation in overweight and obese females. British Journal of Nutrition 109(11): 2031-2035.

Goodman, C., S. Fawcett and S. Barringer. 2002. Flavor, viscosity, and color analyses of hot and cold break tomato juices. Journal of Food Science 67(1): 404-408.

Hensher, D.A., W.H. Greene and C.G. Chorus. 2013. Random regret minimization or random utility maximization: an exploratory analysis in the context of automobile fuel choice. Journal of Advanced Transportation 47(7): 667-678.

Hensher, D.A., W.H. Greene and J.M. Rose. 2006. Deriving willingness-to-pay estimates of travel-time savings from individual-based parameters. Environment and Planning A 38(12): 2365-2376.

House, L.A., Z. Gao, T.H. Spreen, F.G. Gmitter, M.F. Valim, A. Plotto and E.A. Baldwin. 2011. Consumer preference for mandarins: implications of a sensory analysis. Agribusiness 27(4): 450-464.

Jones, M.S., L.A. House and Z. Gao. 2015. Respondent screening and revealed preference axioms: testing quarantining methods for enhanced data quality in web panel surveys. Public Opinion Quarterly 79(3): 687-709.

Klee, H.J. 2015. Heirloom variety trials. Available at: http://hos.ufl.edu/kleeweb/newcultivars.html.

Lawless, H.T. and H. Heymann. 2010. Sensory evaluation of food: principles and practices. Springer Science \& Business Media, New York, NY, USA.

Mesías Díaz, F.J., F. Martínez-Carrasco Pleite, J. Miguel Martínez Paz and P. Gaspar García. 2012. Consumer knowledge, consumption, and willingness to pay for organic tomatoes. British Food Journal 114(3): 318-334.

Petrin, A. and K. Train. 2003. Omitted product attributes in discrete choice models (No.W9452). National Bureau of Economic Research: 1-22.

Putnam, A. 2013. Florida agriculture by the numbers. Avaliable at: http://tinyurl.com/yah7flgt. Pp. 180. 
Sheth, J.N., B.I. Newman and B.L Gross. 1991. Why we buy what we buy: a theory of consumption values. Journal of Business Research 22(2): 159-170.

Stefani, G., D. Romano and A. Cavicchi. 2006. Consumer expectations, liking and willingness to pay for specialty foods: do sensory characteristics tell the whole story? Food Quality and Preference 17(12): $53-62$.

Train, K.E. 2009. Discrete choice methods with simulation. Cambridge University Press, Cambridge, UK.

USCB. 2012. Age and sex composition: 2010. Sep 20. Avaliable at: http://www.census.gov/prod/cen2010/ briefs/c2010br-03.pdf.

USDA. 2010. U.S. tomato statistics. Sep 20. Avaliable at: http://tinyurl.com/7scuqd6.

Zhu, Y., H.J. Klee, P.J. and Sarnoski. 2018. Development and characterization of a high quality plum tomato essence. Food Chemistry 267: 337-343. 
